\title{
Validity of the work productivity and activity impairment questionnaire - general health version in patients with rheumatoid arthritis
}

\author{
Wei Zhang ${ }^{1,2}$, Nick Bansback', Annelies Boonen ${ }^{3}$, Adam Young ${ }^{4}$, Amitabh Singh ${ }^{5}$, Aslam H Anis A $^{1,2^{*}}$
}

\begin{abstract}
Introduction: The Work Productivity and Activity Impairment (WPAI) questionnaire is a well validated instrument to measure impairments in work and activities. However, its validation among patients with rheumatoid arthritis (RA) has not been well established. The present study's purpose is to evaluate the construct validity of the WPAl-general health version among RA patients and its ability to differentiate between RA patients with varying health status.

Methods: Patients who were enrolled in the Early Rheumatoid Arthritis Network cohort and were employed at their most recent follow-up were recruited into this sub-study. A questionnaire battery incorporating the WPAI was administered along with a number of health outcomes including the Multidimensional Health Assessment Questionnaire, fatigue and patient assessment of disease activity. The construct validity of the WPAl was tested by the correlations between the WPAI and the health outcomes and other measures of productivity. Student's $t$ tests were used to identify whether the WPAI outcomes differed between the two levels of heath status based on the median of health outcomes.
\end{abstract}

Results: A total of 150 patients completed the WPAl questionnaire. The average age was 52 years old and the disease duration was 37.5 months since the first rheumatology visit. Of the 137 patients who were working for pay, 26 reported missing work in the past week due to their health problem, accounting for $45.5 \%$ of their working time (absenteeism). While 123 patients were working, 24\% of their work was impaired due to their health problem (presenteeism). In addition, 33\% of the patients' regular daily activities (activity impairment) had been prevented due to their health problems. There were moderate correlations between the WPAI absenteeism and function, pain, fatigue, and disease severity $(r=0.34$ to 0.39 ). The WPAl presenteeism and activity impairment were strongly correlated with the health outcomes (0.67 to 0.77). Patients with more severe disease status (for example, low/high functional disability by median) had significantly higher absenteeism (4\%/15\%), presenteeism (15\%/39\%), and activity impairment (19\%/53\%) than those with less severe disease status.

Conclusions: The WPAI is a valid questionnaire for assessing impairments in paid work and activities in RA patients and for measuring the relative differences between RA patients with different health status.

\section{Introduction}

Rheumatoid arthritis (RA) is the most common form of inflammatory arthritis with a prevalence rate of about $1 \%$ and an annual incidence of 3 per 10,000 adults [1]. There is considerable evidence that RA can impact patients' productivity even during the very early phase of the disease. According to Burton et al., the time between RA

\footnotetext{
* Correspondence: aslam.anis@ubc.ca

'Centre for Health Evaluation and Outcome Sciences, St Paul's Hospital, 620-

1081 Burrard Street, Vancouver, BC V6Z 1Y6, Canada

Full list of author information is available at the end of the article
}

onset until $50 \%$ probability of being permanently work disabled varied from 4.5 to 22 years [2]. Merkesdal et al. found that within the first three years of RA, there was an average of 82 days of sick leave per person-year and $26 \%$ of patients lost work because of RA [3]. Sick leave was more significant in the first year with an average of 113 days. In a study on patients with inflammatory joint conditions present for $<12$ months, Geuskens et al. found that $26 \%$ of all patients and $35 \%$ of the patients with RA reported more than two weeks of sick leave in the past six months [4]. In terms of the impact of RA on 
unpaid work, a recent clinical trial showed that at baseline patients with RA reported 9.2 missed days of household work and 11.2 days with productivity less than or equal to $50 \%$ in household work in one month [5]. Another trial at baseline found that RA patients got about 11 hours of unpaid or paid help to take over their unpaid work [6]. In the literature, functional disability has consistently been found to be associated with work disability [7-9]. In addition, pain and poor physical functioning were also associated with increased sick leave and reduced productivity at work $[4,10]$.

In general, the impact of RA on paid work includes employed people missing time from work (absenteeism), reduced performance while at work (presenteeism), reduced routine working hours through changing or even losing jobs (employment status change). The impact on unpaid work usually refers to the impact of health problems on regular daily activities such as household work, shopping, and child care.

The Work Productivity and Activity Impairment (WPAI) questionnaire is an instrument to measure impairments in both paid work and unpaid work [11,12]. It measures absenteeism, presenteeism as well as the impairments in unpaid activity because of health problem during the past seven days. It has been validated to quantify work impairments for numerous diseases such as asthma, psoriasis, irritable bowel syndrome (IBS), ankylosing spondylitis (AS) and Crohn's disease [12-15]. In addition, the WPAI questionnaire has been used to compare work impairments between treatment groups in clinical (studies and) trials or between subjects with different disease severity levels [13-18]. However, the validation of this instrument among patients with RA has not been well established.

The objective of the study is to evaluate the construct validity of the WPAI-general health version (WPAI-GH) among RA patients and its ability to differentiate between RA patients with varying health status.

\section{Materials and methods Study design}

This study is a cross-sectional study. Patients were recruited from a UK based registry of RA, the Early Rheumatoid Arthritis Network (ERAN), which is a group of rheumatology centres in the UK and Eire with an interest in treatment patterns and outcome in patients with recently diagnosed RA in normal clinical settings. Patients had already consented to take part in the ERAN research study. Patients who reported they were employed at their most recent follow-up with ERAN were invited to participate in this substudy. Those who agreed were sent a questionnaire battery. The questionnaire battery including the WAPI-GH and health outcome measures was administered at one time point. The
WPAI-GH was used to measure the patients' work impairments. Ethical approval was gained from West Herts Multi-centre Research Ethics Committee, UK.

\section{WPAI-GH outcomes}

The WPAI-GH consists of six questions: 1 = currently employed; 2 = hours missed due to health problems; 3 = hours missed other reasons; $4=$ hours actually worked; $5=$ degree health affected productivity while working (using a 0 to 10 Visual Analogue Scale (VAS)); 6 = degree health affected productivity in regular unpaid activities (VAS) $[11,12]$. The recall period for the questions 2 to 6 is seven days. Four main outcomes can be generated from the WPAI-GH and expressed in percentages by multiplying the following scores by $100: 1)$ percent work time missed due to health $=\mathrm{Q} 2 /(\mathrm{Q} 2+\mathrm{Q} 4)$ for those who were currently employed; 2) percent impairment while working due to health $=\mathrm{Q} 5 / 10$ for those who were currently employed and actually worked in the past seven days; 3$)$ percent overall work impairment due to health $\mathrm{Q} 2 /(\mathrm{Q} 2+\mathrm{Q} 4)+((1-\mathrm{Q} 2 /(\mathrm{Q} 2+$ $\mathrm{Q} 4)) \times(\mathrm{Q} 5 / 10))$ for those who were currently employed; 4) percent activity impairment due to health Q6/10 for all respondents $[11,12]$. For those who missed work and did not actually work in the past seven days, the percent overall work impairment due to health will be equal to the percent work time missed due to health.

\section{Construct validity: relation with health}

We selected a number of instruments measuring health status that we believed would be correlated with productivity outcomes. The Multidimensional Health Assessment Questionnaire (MDHAQ) is a validated one-page questionnaire including a measure of functional disability, pain, and patient global health estimate [19]. The scoring of the MDHAQ was as follows: a) Function score: 10 activities of daily living (ADL) were scored 0 to 3, $0=$ "without any difficulty", $1=$ "with some difficulty", 2 = "with much difficulty", and $3=$ "unable to do." To be consistent with the Health Assessment Questionnaire score (HAQ), the sum of $10 \mathrm{ADL}$ scores was divided by 10 to give a score of 0 to 3 ; b) Pain VAS; c) Patient global estimate VAS on health impact. Fatigue VAS was used to measure patient assessment of fatigue problem. Patient global assessment (PtGA) of disease activity was used as a proxy of disease activity. Previous studies have found a strong correlation between the patient global assessment of disease activity and the disease activity score including 28 -joint counts, with a VAS score greater than 40 indicating high disease activities [20]. All the VAS scales were presented as 21 circles to facilitate scoring without a ruler and an arithmetic scale of 0 to 10 in 0.5 unit increments was printed below the circles. 


\section{Construct validity; relation with other measure of productivity}

Questions on productivity adapted from alternative questionnaires were also included to assess the consistency of responses. They included the number of absent workdays in the past three months, a question adapted from the PROductivity and DISease Questionnaire (PRODISQ) [21], and questions adapted from Health and Labour Questionnaire (HLQ) [22,23] asking about lost hours due to presenteeism (the difference between the numbers of hours actually worked in the past seven days and the estimated number of hours used to complete the same work if patients did not experience any health problems) and the impact of health on unpaid work activities (hours of getting help with unpaid work activities in the past seven days).

In addition, the ability of the WPAI-GH to discriminate between better and worse health states was tested by dividing patients into two groups based on the median of the scores for function, pain, health impact, fatigue and disease activity (Better status: $\leq$ median; Worse status: >median).

\section{Analysis}

We measured the extent to which WPAI productivity outcomes were correlated with health status outcomes and the productivity questions adapted from alternative questionnaires. Due to the skewed nature of the productivity outcome data, nonparametric correlation (Spearman's correlation coefficient) was used to assess construct validity.

For a comparison between two groups, the effect size, the standardized mean difference between two groups on a measured outcome, was calculated for all WPAI-GH outcomes. An effect size of one indicates a change in magnitude equivalent to one standard deviation. According to Cohen [24,25], the absolute value of effect sizes (d) can be categorized as small ( $\mathrm{d}=0.2$ to 0.5$)$, medium ( $\mathrm{d}=$ 0.5 to 0.8$)$, or large $(\mathrm{d}>0.8)$. A larger effect size indicates better discriminative ability. Student $t$ tests were used to identify whether WPAI outcomes differed between the two levels of heath status. Wilcoxon tests were also used due to the skewed nature of the productivity outcome data.

\section{Results}

A total of 354 patients believed to be in some sort of work in ERAN were contacted for the study and 186 (53\%) agreed to take part in the study and were sent the questionnaires. One hundred and fifty-two patients sent back the questionnaire but two of these patients did not respond to the questions in the WPAI so that no WPAI outcomes could be calculated. Therefore, a total of 150 patients were included in the analysis. Among the 150 patients, the average age was 52 years old and $72 \%$ were female (Table 1 ). The sample's disease duration was 37.5 months since their first rheumatology visit. Patients had relatively mild function (0.6), pain (3.6), fatigue (4.6) and disease activity (3.6). Of the 137 (91\%) patients that were working for pay, 26 (19\%) reported missing work (absenteeism) in the past week due to their health, accounting for $45.5 \%$ of their working time (Table 2). While 123 patients were working, $24 \%$ of their actual work was impaired due to their health problem (presenteeism) with only 34 (28\%) patients reported no such loss. In addition, $33 \%$ of the patients' regular daily activities had been prevented due to their health problems.

For the correlation analysis between the WPAI productivity outcomes and the health status outcomes, all the correlations were in the logical direction and were highly significant (Table 3 ). There were moderate correlations between percent work time missed due to health and function, pain, fatigue, health impact, and disease severity $(0.34$ to 0.39$)$. The other three WPAI outcomes were strongly correlated with all of the health status outcomes (0.67 to 0.77$)$.

The number of absent workdays in the past three months was about 4.4 (standard deviation (SD): 10.5) days. The number of hours lost due to presenteeism in the past seven days was 1.4 (2.8) hours. Overall, patients got 4.0 (8.3) hours of help with their unpaid work activities in the past seven days. The percent of work time missed due to health was moderately correlated with number of absent workdays in the past three months $(r=0.56)$. The correlation between impairment while working and hours lost due to presenteeism was 0.39 and that between activity impairment and hours of getting help on unpaid work activities was 0.39 .

When the patients were divided into two groups according to the median of each health status outcome

\section{Table 1 Demographics and health status}

\begin{tabular}{|c|c|c|}
\hline Variables $(n=150)$ & Mean (SD) & Median (Q1 to Q3) \\
\hline$\overline{\text { Age }}$ & $52.1(10.0)$ & 52.9 (45.6 to 60.0$)$ \\
\hline $\begin{array}{l}\text { Duration since onset of } \\
\text { symptom (months) }\end{array}$ & $48.7(23.2)$ & 46.0 (33.0 to 60.0) \\
\hline $\begin{array}{l}\text { Duration since first clinic } \\
\text { visit (months) }\end{array}$ & $37.5(18.3)$ & 35.7 (23.7 to 50.9) \\
\hline Function (0 to 3 ) & $0.6(0.5)$ & 0.5 (0.2 to 0.9$)$ \\
\hline Pain (0 to 10 ) & $3.6(2.5)$ & $3.0(1.5$ to 5.5$)$ \\
\hline $\begin{array}{l}\text { Pt global estimate } \\
(0 \text { to } 10)\end{array}$ & $3.0(2.4)$ & $2.5(1.0$ to 5.0$)$ \\
\hline Fatigue (0 to 10 ) & $4.6(2.9)$ & 5.0 (2.0 to 7.0$)$ \\
\hline \multirow[t]{2}{*}{ PtGA (0 to 10$)$} & $3.6(2.6)$ & $3.0(1.5$ to 5.5$)$ \\
\hline & $n$ & $\%$ \\
\hline Female & 108 & 72.0 \\
\hline
\end{tabular}

Pt global estimate, patient global estimate on health impact; PtGA, patient global assessment of disease activity; Q1, first quartile; Q3, third quartile. 
Table 2 WPAl outcomes

\begin{tabular}{|c|c|c|c|}
\hline Variables & $n$ & Mean (SD) & Median (Q1 to Q3) \\
\hline Patients working for pay & 137 & & \\
\hline Percent work time missed due to health & 136 & $8.7(25.2)$ & $0(0$ to 0$)$ \\
\hline Percent work time missed due to health (those with missed time $>0$ ) & 26 & $45.5(41.2)$ & $18(12$ to 100$)$ \\
\hline Patients who actually worked in the past seven days & 123 & & \\
\hline Percent impairment while working due to health & 122 & $24.0(22.7)$ & $20(0$ to 40$)$ \\
\hline Percent impairment while working due to health (those with \% impairment while working $>0$ ) & 88 & $33.3(20.1)$ & $30(20$ to 50$)$ \\
\hline Percent overall work impairment due to health & 135 & $29.1(29.8)$ & $20(0$ to 46$)$ \\
\hline All patients & 150 & & \\
\hline Percent activity impairment due to health & 150 & $33.3(27.6)$ & $30(10$ to 60$)$ \\
\hline Percent activity impairment due to health (those with $\%$ activity impairment $>0$ ) & 123 & $40.7(25.1)$ & 30 (20 to 60$)$ \\
\hline
\end{tabular}

Q1, first quartile; Q3, third quartile.

variable, each of WPAI productivity outcomes was significantly lower among patients with better health status than patients with worse health status (Table 4). For example, patients with low functional disability (lower than median) had a significantly lower percentage of work time missed due to health (4 vs. 15), lower percentage of impairment while working due to health (15 vs. 39 ), and lower percentage of activity impairment due to health (19 vs. 53) than those with high functional disability. According to the effect size, WPAI outcomes had large discriminative abilities (1.10 to 1.79) except the percent work time missed due to health which showed a medium discriminative ability ( 0.43 to 0.63 ). The test results from $t$ tests and Wilcoxon tests agreed (only the results of the $t$ tests were reported).

\section{Discussion}

This is the first study to examine the construct validity of the WPAI-GH in a relatively large sample of patients with RA. The results support that the WPAI-GH displays construct validity as measured by moderate to strong correlations with all health status measures in terms of functional disability, pain, fatigue and disease activity (Table 3 ). As such, it appears that the WPAI productivity outcomes are assessing constructs that are relevant and important to patients with RA. However, the WPAI is moderately correlated with other productivity outcomes such as hours lost due to presenteeism and hours of getting help on unpaid work activities measured using the questions adapted from the HLQ.
This may suggest that it measures another aspect of presenteeism and unpaid work productivity in comparison with the HLQ. In addition, according to the effect size analysis and paired test, the WPAI-GH could discriminate across health status with worse score being associated with measures indicating worse health status among the patients with RA. The results demonstrate the validity of the WPAI-GH is consistent with previous WPAI validation results for other diseases.

It is interesting that absenteeism (percent of work time missed) correlates less with health than presenteeism (impairment while working). This may be because the decision to stay home depends on more contextual factors than impairments while working that are related to the diseases; for example, the type of work, the fear to be a burden to colleagues, attitude towards work, consequence for income, fear to lose work, and so on. This suggests that absenteeism measures another dimension of the impact of the disease which is not measured by other health outcome instruments. One previous item response theory study in AS showed that work participation did not fit the unidimensionality of all other categories/domains of the International Classification of Functioning, Disability and Health that refer to body functions, body structures, activities and participation [26]. There is also the role of the social security system that is expected to influence more absenteeism than presenteeism/activity impairment, which makes absenteeism less comparable internationally [27]. However, the high correlation between impairment while working/activity

Table 3 Spearman correlations between WPAI outcomes and health status outcomes

\begin{tabular}{|c|c|c|c|c|c|}
\hline & Function & Pain & Pt global estimate & Fatigue & PtGA \\
\hline Percent work time missed & 0.39 & 0.36 & 0.36 & 0.37 & 0.34 \\
\hline Percent impairment while working & 0.69 & 0.75 & 0.74 & 0.67 & 0.76 \\
\hline Percent overall work impairment & 0.67 & 0.73 & 0.71 & 0.68 & 0.73 \\
\hline Percent activity impairment & 0.73 & 0.77 & 0.77 & 0.68 & 0.77 \\
\hline
\end{tabular}

Pt global estimate, patient global estimate on health impact; PtGA, patient global assessment of disease activity. 
Table 4 WPAI outcomes between two patient groups defined by the median for each health status outcome

\begin{tabular}{lcccccc}
\hline & & Function & Pain & Pt global estimate & Fatigue & PtGA \\
\hline Percent work time missed & Better & $4.2(19.0)^{\ddagger}$ & $1.5(7.2)$ & $2.0(7.7)^{\dagger}$ & $3.9(15.8)^{\ddagger}$ & $1.6(7.1)$ \\
& Worse & $15.5(31.5)$ & $16.3(34.0)$ & $15.6(33.9)$ & $14.5(32.4)$ & $16.9(34.6)$ \\
& Effect size & 0.46 & 0.61 & 0.55 & 0.43 & 0.63 \\
Percent impairment while working & Better & $14.5(18.8)$ & $11.6(15.0)$ & $10.9(13.1)$ & $12.8(16.8)$ & $11.7(14.3)$ \\
& Worse & $39.1(20.1)$ & $39.6(21.1)$ & $40.0(21.7)$ & $38.7(21.0)$ & $41.2(21.0)$ \\
& Effect size & 1.27 & 1.56 & 1.66 & 1.38 & 1.69 \\
Percent overall work impairment & Better & $17.6(24.8)$ & $12.2(16.7)$ & $11.8(15.7)$ & $14.8(22.1)$ & $12.3(16.1)$ \\
& Worse & $46.5(28.2)$ & $47.4(30.0)$ & $47.2(30.3)$ & $46.0(28.9)$ & $48.9(30.1)$ \\
& Effect size & 1.10 & 1.46 & 1.48 & 1.22 & 1.55 \\
Percent activity impairment & Better & $19.0(21.1)$ & $15.7(17.0)$ & $15.1(17.0)$ & $19.6(21.0)$ & $17.5(19.0)$ \\
& Worse & $52.7(23.3)$ & $51.9(24.4)$ & $52.0(23.7)$ & $49.9(25.6)$ & $51.9(24.5)$ \\
& Effect size & 1.53 & 1.73 & 1.79 & 1.30 & 1.58 \\
\hline
\end{tabular}

Pt global estimate, patient global estimate on health impact; PtGA, patient global assessment of disease activity.

If not indicated, $t$ test $P$ values $<0.001 ;{ }^{\dagger}, t$ test $P$ values $<0.01 ;{ }^{\ddagger}, t$ test $P$ values $<0.05$.

Better status, $\leq$ median; Worse status, $>$ median. The median for each health status outcome was shown in Table 1.

impairment and other health outcomes may be partially attributable to the fact that they all use the same measuring 0 to 10 scale.

Among health outcomes, pain and PtGA were more correlated with work impairment and activity impairment than function and fatigue. In the literature, pain was found to be highly associated with reduced productivity at work [10]. However, no previous studies have shown that disease activity is highly correlated with work and activity impairment among people with RA. Further studies are needed to confirm the relationships.

There are two aspects of productivity that are important to measure: first, the work difficulties or work impairments due to health which influence work related quality of life and/or psychosocial impacts such as job satisfaction and stress, and second, the actual productivity losses due to health. The WPAI was designed predominantly to measure the first aspect but has been used in the past to measure and value the productivity losses for economic evaluations. However, the WPAI does not necessarily capture sufficient information to comprehensively measure actual productivity losses. To do so, it requires measures of actual lost time estimators as well as contextual factors such as job type, workplace team dynamics and compensation mechanism (a manuscript from Zhang et al. - in submission).

A total of 186 patients agreed to participate in the study but 150 patients completed WPAI questions and were included in our analysis. To identify whether there were non-response biases, we compared patient characteristics, including age, gender, duration since onset of symptom, duration since fist clinic visit, as well as disease activity score, HAQ and PtGA measured in the most recent follow-up with ERAN, between the 150 patients who were included in the analysis and the 36 patients who were not. No significant differences were found.
A limitation of this study is that no independent employment measure (gold standard) of missed work hours or work impairment while working was used as a validation criterion. Severens et al. investigated the agreement between registered and reported sick leave [28]. They demonstrated that $95 \%$ of the reported days of sick leave matched registered data perfectly when the recall period was limited to two and four weeks. This percentage decreased to $87 \%, 57 \%$, and $51 \%$ for 2,6 , and 12 months, respectively. Reilly et al. assessed the accuracy of self-reported work hours missed measured by the WPAI:IBS version using retrospective diary among patients with IBS [13]. The high convergence of the WPAI:IBS and retrospective diary suggested that self-reports of percentage work hours missed during the past week were accurate.

In terms of work impairment while at work, presenteeism, Lerner et al. established the relationship between their Work Limitation Questionnaire and objective work productivity measures in two types of occupations [29]. However, it is quite difficult to measure the relationship between self-reported and objective measures of productivity at work because the objective measures varied with occupations as well as workplaces and so is the relationship [30]. Zhang et al. have demonstrated that the work productivity loss while at work varies widely with the approach chosen among people with arthritis [31,32]. Future research should focus on assessing the relationship between self report and objective measures of productivity loss and examining which approach provides more accurate measure of productivity loss.

We did not test the reliability of the WPAI-GH among patients with RA in this study. The test-retest reliability of the WPAI has been well established in populations with different diseases [33,34]. We assumed that this would not be different for the population with 
RA. The responsiveness of the WPAI-GH among patients with RA will be tested in a future study.

This is not the first application of WPAI among RA patients. One application of WPAI in RA was a study published as an abstract at 2008 American College of Rheumatology annual scientific meeting [35]. It was used to explore the impact of health problems on presenteeism in patients recently diagnosed with RA as compared to a healthy comparison group. Another application of WPAI was conducted by the Canadian Arthritis Network work productivity study, which was to compare different presenteeism measures among people with arthritis [31,32]. However, in both studies, only the question measuring impairment while working (question 5 of WPAI) was used and the main purposes were not to validate the instrument.

The WPAI has been used to measure work productivity in other diseases such as asthma, psoriasis, irritable bowel syndrome (IBS), ankylosing spondylitis (AS) and Crohn's disease [13-18]. The mean percent work time missed has been reported to be 5.0 for people with asthma [18], 4.4 for people with IBS [13], 9.0 for people with AS [14] and 18.3 for people with Crohn's disease [15], respectively, compared with 8.7 for people with RA in our study population. The percent impairment while working has been reported to be 20.0 in asthma, 15.5 in psoriasis [17], 32.4 in IBS, 41.7 in AS and 40.5 in Crohn's disease compared with 24.0 in RA from our study. Correspondingly, percent activity impairment has been found to be 32.0, 23.7, 41.4, 54.9 and 52.0 compared with 33.3 in our study of RA patients. According to these WPAI outcomes, it shows that RA has a relatively moderate impact on work productivity compared to other diseases. However, even for a certain disease, the WPAI outcomes vary with different levels of severity. Given that our RA population has early disease and therefore typically mild disease severity, the other disease populations compared may have a relatively more severe disease status. Simple comparisons should be made with caution.

\section{Conclusions}

Construct validity and the discriminative ability of the WPAI-GH have been established in this study. Thus, the WPAI-GH is a valid questionnaire for assessing impairments in paid work and activities in RA patients and for measuring the relative differences between RA patients with different health status. The WPAI-GH is useful for measuring productivity outcomes in clinical practice. Further studies are needed to validate a tool for valuing productivity loss in economic analyses.

\section{Abbreviations}

ADL: activities of daily living; AS: ankylosing spondylitis; ERAN: Early Rheumatoid Arthritis Network; HLQ: Health and Labour Questionnaire; IBS: irritable bowel syndrome; MDHAQ: Multidimensional Health Assessment
Questionnaire; PRODISQ: PROductivity and DISease Questionnaire; PtGA: Patient Global Assessment; RA: rheumatoid arthritis; VAS: Visual Analogue Scale; WPAl: Work Productivity and Activity Impairment questionnaire; WPAI$\mathrm{GH}$ : WPAl-general health version.

\section{Acknowledgements}

WZ is a recipient of a Canadian Institutes of Health Research Doctoral Research Award in the Area of Public Health Research and a Canadian Arthritis Network Graduate Award.

\section{Author details}

'Centre for Health Evaluation and Outcome Sciences, St Paul's Hospital, 6201081 Burrard Street, Vancouver, BC V6Z 1Y6, Canada. 'School of Population and Public Health, University of British Columbia, 5804 Fairview Avenue, Vancouver, BC V6T 1Z3, Canada. ${ }^{3}$ Department of Internal Medicine, Division of Rheumatology, University Hospital Maastricht and Caphri Research Institute, P Debyelaan 25, 6229 HX Maastricht, The Netherlands. ${ }^{4}$ Department of Rheumatology, St Albans City Hospital, Waverley Road, St Albans, Herts AL3 5PN, UK. ${ }^{5}$ Inflammation Market Access, Pfizer, Inc. 500 Arcola Road, Dock E-4303 Collegeville, PA 19426, USA.

\section{Authors' contributions}

WZ, NB, AY and AHA were involved in the conceptualization, design, data acquisition and interpretation. $A B$ and $A S$ participated in the conceptualization and data interpretation. WZ performed data analysis and drafted the manuscript. $N B, A B, A Y, A S$ and $A H A$ critically revised the manuscript. All authors read and approved the final manuscript.

\section{Competing interests}

This study was funded by Wyeth (now Pfizer). The Arthritis Research Centre of Canada, where AHA is a senior research scientist, has received a research grant from Wyeth. ERAN has received funding from Wyeth Pharmaceuticals and the Healthcare Commission. AS was an employee of Wyeth and owned its stocks/shares at the time of the study.

Received: 1 April 2010 Revised: 3 September 2010

Accepted: 22 September 2010 Published: 22 September 2010

\section{References}

1. Gabriel SE: The epidemiology of rheumatoid arthritis. Rheum Dis Clin North Am 2001, 27:269-281.

2. Burton W, Morrison A, Maclean R, Ruderman E: Systematic review of studies of productivity loss due to rheumatoid arthritis. Occup Med (Lond) 2006, 56:18-27.

3. Merkesdal S, Ruof J, Schoffski O, Bernitt K, Zeidler H, Mau W: Indirect medical costs in early rheumatoid arthritis: composition of and changes in indirect costs within the first three years of disease. Arthritis Rheum 2001, 44:528-534.

4. Geuskens GA, Hazes JM, Barendregt PJ, Burdorf A: Work and sick leave among patients with early inflammatory joint conditions. Arthritis Rheum 2008, 59:1458-1466.

5. Osterhaus JT, Purcaru O, Richard L: Discriminant validity, responsiveness and reliability of the rheumatoid arthritis-specific Work Productivity Survey (WPS-RA). Arthritis Res Ther 2009, 11:R73.

6. Zhang W, Bansback N, Guh D, Li X, Nosyk B, Marra CA, Anis AH: Short-term influence of adalimumab on work productivity outcomes in patients with rheumatoid arthritis. J Rheumatol 2008, 35:1729-1736.

7. de Croon EM, Sluiter JK, Nijssen TF, Dijkmans BA, Lankhorst GJ, FringsDresen $\mathrm{MH}$ : Predictive factors of work disability in rheumatoid arthritis: a systematic literature review. Ann Rheum Dis 2004, 63:1362-1367.

8. Eberhardt K, Larsson BM, Nived K, Lindqvist E: Work disability in rheumatoid arthritis-development over 15 years and evaluation of predictive factors over time. J Rheumatol 2007, 34:481-487.

9. Kessler RC, Maclean JR, Petukhova M, Sarawate CA, Short L, Li TT, Stang PE: The effects of rheumatoid arthritis on labor force participation, work performance, and healthcare costs in two workplace samples. $J$ Occup Environ Med 2008, 50:88-98.

10. Geuskens GA, Hazes JM, Barendregt PJ, Burdorf A: Predictors of sick leave and reduced productivity at work among persons with early inflammatory joint conditions. Scand J Work Environ Health 2008, 34:420-429. 
11. Reilly MC, Zbrozek AS, Dukes EM: The validity and reproducibility of a work productivity and activity impairment instrument.

Pharmacoeconomics 1993, 4:353-365.

12. Reilly Associates Health Outcomes Research. [http://www.reillyassociates. net].

13. Reilly MC, Bracco A, Ricci J, Santoro J, Stevens T: The validity and accuracy of the Work Productivity and Activity Impairment questionnaire Irritable bowel syndrome version (WPAl:IBS). Alimentary Pharmacology and Therapeutics 2004, 20:459-467.

14. Reilly MC, Gooch KL, Wong RL, Kupper H, van der Heijde D: Validity, reliability and responsiveness of the Work Productivity and Activity Impairment Questionnaire in ankylosing spondylitis. Rheumatology (Oxford) 2010, 49:812-819.

15. Reilly MC, Gerlier L, Brabant Y, Brown M: Validity, reliability, and responsiveness of the work productivity and activity impairment questionnaire in Crohn's disease. Clin Ther 2008, 30:393-404.

16. Revicki DA, Willian MK, Menter A, Gordon KB, Kimball AB, Leonardi $C L$, Langley RG, Kimel M, Okun M: Impact of adalimumab treatment on patient-reported outcomes: results from a Phase III clinical trial in patients with moderate to severe plaque psoriasis. J Dermatolog Treat 2007, 18:341-350.

17. Pearce DJ, Singh S, Balkrishnan R, Kulkarni A, Fleischer AB, Feldman SR: The negative impact of psoriasis on the workplace. J Dermatolog Treat 2006, 17:24-28.

18. Chen H, Blanc PD, Hayden ML, Bleecker ER, Chawla A, Lee JH, TENOR Study Group: Assessing productivity loss and activity impairment in severe or difficult-to-treat asthma. Value Health 2008, 11:231-239.

19. Pincus T, Swearingen C, Wolfe F: Toward a multidimensional Health Assessment Questionnaire (MDHAQ): assessment of advanced activities of daily living and psychological status in the patient-friendly health assessment questionnaire format. Arthritis Rheum 1999, 42:2220-2230.

20. Kobelt $G$, Lindgren $P$, Lindroth $Y$, Jacobson $L$, Eberhardt $K$ : Modelling the effect of function and disease activity on costs and quality of life in rheumatoid arthritis. Rheumatology (Oxford) 2005, 44:1169-1175.

21. Koopmanschap MA: PRODISQ: a modular questionnaire on productivity and disease for economic evaluation studies. Expert Rev Pharmacoecon Outcomes Res 2005, 5:23-28.

22. van Roijen L, Essink-Bot ML, Koopmanschap MA, Bonsel G, Rutten FF: Labor and health status in economic evaluation of health care. The Health and Labor Questionnaire. Int J Technol Assess Health Care 1996, 12:405-415.

23. The health and labour questionnaire (manual). [http://publishing.eur.nl/ir/ repub/asset/1313/bmgimt20000609160629.pdf].

24. Cohen J: A power primer. Psychol Bull 1992, 112:155-159.

25. Cohen J: Statistical Power Analysis for the Behavioural Sciences, 2nd edition. Hillsdale, NJ: Lawrence Erlbaum Association; 1988.

26. Cieza A, Hilfiker R, Boonen A, van der Heijde D, Braun J, Stucki G: Towards an ICF-based clinical measure of functioning in people with ankylosing spondylitis: a methodological exploration. Disabil Rehabil 2009, 31:528-537.

27. Boonen A, van der Heijde D, Landewe R, Spoorenberg A, Schouten $H$, Rutten-van Molken M, Guillemin F, Dougados M, Mielants H, de Vlam K, van der Tempel H, van der Linden S: Work status and productivity costs due to ankylosing spondylitis: comparison of three European countries. Ann Rheum Dis 2002, 61:429-437.

28. Severens JL, Mulder J, Laheij L, Verbeek V: Precision and accuracy in measuring absence from work as a basis for calculating productivity costs in The Netherlands. Social Science and Medicine 2000, 51:243-249.

29. Lerner D, Amick BC, Lee JC, Rooney T, Rogers WH, Chang H, Berndt ER: Relationship of employee-reported work limitations to work productivity. Med Care 2003, 41:649-659.

30. Prasad $M$, Wahlqvist $P$, Shikiar $R$, Shih $Y C$ : A review of self-report instruments measuring health-related work productivity: a patientreported outcomes perspective. Pharmacoeconomics 2004, 22:225-244.

31. Zhang W, Bansback N, Beaton D, Lacaille D, Gignac M, Badley E, Bombardier $\mathrm{C}$, Anis AH: How is reduced performance at work (presenteeism) associated with measures of disease severity in patients with osteoarthritis (OA) and rheumatoid arthritis (RA)? [abstract]. Ann Rheum Dis 2008, 67:583.

32. Zhang W, Gignac MA, Beaton D, Tang K, Anis AH, Canadian Arthritis Network Work Productivity Group: Productivity loss due to presenteeism among patients with arthritis: estimates from 4 instruments. J Rheumatol 2010, 37:1805-1814.

33. Bushnell DM, Reilly MC, Galani C, Martin ML, Ricci JF, Patrick DL, McBurney CR: Validation of electronic data capture of the Irritable Bowel Syndrome-Quality of Life Measure, the Work Productivity and Activity Impairment Questionnaire for Irritable Bowel Syndrome and the EuroQol. Value Health 2006, 9:98-105.

34. Ciconelli RM, Soarez PC, Kowalski CC, Ferraz MB: The Brazilian Portuguese version of the Work Productivity and Activity Impairment: General Health (WPAI-GH) Questionnaire. Sao Paulo Med J 2006, 124:325-332.

35. Braakman-Jansen LM, Taal E, Kuper I, van de Laar MA: Productivity loss at work in patients with early rheumatoid arthritis [abstract]. American College of Rheumatology annual scientific meeting (presentation 1275), 2008.

doi:10.1186/ar3141

Cite this article as: Zhang et al:: Validity of the work productivity and activity impairment questionnaire - general health version in patients with rheumatoid arthritis. Arthritis Research \& Therapy 2010 12:R177.

\section{Submit your next manuscript to BioMed Central and take full advantage of:}

- Convenient online submission

- Thorough peer review

- No space constraints or color figure charges

- Immediate publication on acceptance

- Inclusion in PubMed, CAS, Scopus and Google Scholar

- Research which is freely available for redistribution 